specimen it could easily be transferred to the clear Latin italics.

"Thus the transference of (bphioglossum granulatum, Heer, to Pinus granulata (Heer) would indicate that an exceedingly doubtful determination had been replaced by one with some scientific basis. Any worker in another branch of science, seeing (1), Aramulatum, in Gothic, would be warned at least to look into the grounds for the determination for himself before he-let us imagine-used the record for his stratigraphic work in correlating horizons, or in writing up the early history of the Ophioglossaceæ, when he would otherwise assume that the living genus was represented in Cretaceous times in the Ambay Clays of North America. This is merely an illustration of what is very widely spread in fossil botany; but it may serve to give point to the general proposition that the time has come when it would be of real service to the science to attempt a conscientious distinction between valuable and doubtful determinations, and that Gothic lettering might give us an easy indicator.

"The need for this is all the greater, because the results of palæobotany touch so many other fields of research, in animal palæontology, geology, and palæogeography, as well as botany itself. Workers from these other fields are seldom able to estimate the evidence that they are taking to build into their own work, even had they the time to go into the details; and thus a single error gets widely disseminated. Often it is not entirely the fault of the one who originally described the fossil, for he may say in his text that the nature of the specimen is doubtful, and that, in default of better evidence, he gives a certain name with hesitation. That name, however, once given, is quoted and put into lists without being in any way distinguished from the rest; and the results are detrimental to the advance of true knowledge in every way. It is no solution to call every leaf, as some conscientious workers do, 'Phyllites': different things, however doubtful, must have distinct names, and the use of Gothic characters for the very doubtful ones would greatly tend to 'create confidence 'in the science of palæobotany."

\section{Marie C. Stopes.}

\section{The Unit of Momentum.}

DoubTLEs all teachers of experience are agreed that in dealing with the measurable quantities considered in mathematics and physics there is great difficulty in giving to students a clear idea of the quantities measured unless a definite name be given to the unit in terms of which measurement is made.

Until the word " radian" was introduced, circular measure was a stumbling-block to all beginners in trigonometry; the sentences " the circular measure of this angle is $\mathrm{x} .7$ " and "arc over radius equals 1.7 " make little impression on the untutored mind; but the sentence "this angle contains 1.7 radians - the radian being rather more than $57^{\circ}$ " is as easy of comprehension as "the value of this is $2 \frac{1}{3}$ guineas-the guinea being $2 \mathrm{I}$ shillings." So in electricity, without the names ampere, volt, ohm, \&c. the learner would be-as he was thirty years ago-lost in hopeless vagueness.

In mechanics we have given names to almost all the units; why not give one to the unit of momentum? I venture to suggest for general use the names which I have myself made use of for many years, and have found helpful in inducing clear thinking on the part of my students; they are analogous to the names of the units of work.

Thus the work done by a force $\mathrm{I} \mathrm{lb}$. acting for $\mathrm{I} \mathrm{ft}$. is one $\mathrm{ft}-\mathrm{lb}$

The momentum produced by a force I $1 b$. acting for I sec. is one sec-lb.

The work done by a force $\mathrm{I}$ poundal acting for $\mathrm{I} f \mathrm{ft}$. is one ft-poundal.

The momentum produced by a force I poundal acting for $\mathrm{I}$ sec. is one sec-poundal.

The work done by a force $I$ dyne acting for $I \mathrm{~cm}$. is one cm-dvne (erg)

The momentum produced by a force I dyne acting for I sec. is one sec-dyne.

NO. 2 I96, VOL. 887
Similarly we may speak of a sec-ton and a sec-tondal.

The advantage of the above names is that they emphasise the essential distinction between momentum and kinetic energy, viz. that one measures what I may call the timeeffect of a force and the other its space-effect; or, to put it differently, when we know the momentum of a moving body we know hore long a given force must act to produce the motion, and when we know its kinetic energy we know how far the force must act. This point of view seems to me far more desirable than the suggestion to the beginner that momentum is $m v$, or " mass X velocity"; such a suggestion he must either receive in deadly apathy or he must worry his brain with the impossible task of trying to conceive how mass can be multiplied by velocity : his teacher may try to slur over the difficulty for him by a word-juggling substitution, and say momentum is the product of mass and velocity; but then, what is a product? In the mathematical sense of the word it is the result of multiplication; in the non-mathematical sense it is anything resulting from or produced from certain others; and in this latter sense kinetic energy is just as much the product of mass and velocity as momentum is. So, also, the time-honoured but vague phrase "quantity of motion" could be used to express kinetic energy with quite as much aptness as to express momentum.

Using these names, we would teach-

"The momentum of $m \mathrm{lb}$. moving at $v$ f.s. is $m v$ secpoundals, or $m v / g$ sec-lbs. ; its K.E. is $\frac{1}{2} m v^{2} \mathrm{ft}$-poundals, or $\frac{1}{2} m v^{2} / g$ ft-lbs." "The momentum of $m$ grams moving at $v$ c.s. is $m v$ sec-dynes; its K.E. is $\frac{1}{2} m v^{2}$ ergs (cm-dynes).'

The University, Bristol, November 7 . F. R. BARRELL.

I AM in the habit of saying, " the amount of momentum is 12 in C.G.S. units" or "the amount of momentum is 12 in engineers' units." The use of such a complex name as " gram-centimetre per second" would be absurd. Now Mr. Barrell has made an excellent suggestion; the names sec-dyne with all students, and sec-pound with such students as use engineers' units, are not only short and easy to remember, but they keep before the student the fundamental fact that force is time rate of change of momentum. It seems to me, however, that at the start we must define momentum as $m v$, and boys must from the start learn that they are no longer multiplying mere numbers. I never found that a boy had any difficulty if his master did not create one. A boy knows at once that if a distance of 100 yards is passed over in 20 seconds there is an average speed of 5 yards per second; he has no difficulty in dividing space by time, but his teacher may create great confusion in his mind if he philosophises about it. JOHN PERRY.

\section{Fish and Drought}

IN my letter on "Fish and Drought" published in NATURE of November 23 there is an error, due, without doubt, to a mistake in my MS., which may confuse the reader. In the tenth line from the bottom of the righthand column of p. 108 the word " north" occurs; it should read "south."

It has been pointed out to me by friends who have read the letter that the final paragraph is rather difficult to follow. With your permission I beg to take this opportunity of rectifying its expression, as follows :-

In conclusion, I think that the observations above recorded show that the material of geological formations need not necessarily have been "laid down"; it may have been produced in situ like the mud in the ditch round the Park of Marchais, and that the enclosure in it of animal remains may have been in some cases due to a voluntary act of self-inhumation, undertaken, perhaps usually, with a view to self-protection. They also show that two neighbouring strata, the one carrying abundance of life and the other being destitute of it, may nevertheless be contemporaneous in date and conterminous in locality of formation.

November 26 . 